\title{
„CHildhood Allergy and tolerance: bioMarkers and Predictors (CHAMP) and quality of life"
}

Jana Eckert ${ }^{1}$, Julia Kahle ${ }^{2}$, Andreas Böck ${ }^{1}$, Kathrin Zeber ${ }^{1}$, Kathrin Urner ${ }^{1}$, Wolfgang Greiner $^{3}$, Simone Kreimeier ${ }^{3}$, Kirsten BEYER ${ }^{4}$, Josefine Dobbertin-Welsch ${ }^{5}$, Eckard Hamelmann $^{3}$, Ines Gellhaus ${ }^{3}$, Christina Schorlemer ${ }^{3}$, Michael Kabesch ${ }^{6}$, Parastoo Kheiroddin $^{6}$, Erika von Mutius ${ }^{7}$, Martin Depner ${ }^{8}$, Daniel Walter ${ }^{1}$, Gesine Hansen ${ }^{9}$, Stephanie DeStefano ${ }^{9}$, Sabine Schnadt ${ }^{10}$, and Bianca Schaub ${ }^{11}$

${ }^{1}$ Dr von Haunersches Kinderspital Kinderklinik und Kinderpoliklinik der Ludwig Maximilian Universitat Munchen

${ }^{2}$ German Allergy and Asthma Association

${ }^{3}$ Bielefeld University

${ }^{4}$ Charite Medical Faculty Berlin

${ }^{5}$ Charite University Hospital Berlin

${ }^{6}$ University of Regensburg

${ }^{7}$ Munich University Hospital Dr von Hauner Children's Hospital

${ }^{8}$ Helmholtz-Zentrum Muenchen

${ }^{9}$ Hannover Medical School

${ }^{10}$ German Allergy and Asthma Foundation

${ }^{11}$ University Children's Hospital Munich

March 29, 2021

\section{Hosted file}

202103023_CHAMP Publication_letter_main.pdf available at https://authorea.com/users/387299/ articles/515878--childhood-allergy-and-tolerance-biomarkers-and-predictors-champ-andquality-of-life

\section{Hosted file}

20210318_CHAMP Publication_ letter_Tables.pdf available at https://authorea.com/users/387299/ articles/515878--childhood-allergy-and-tolerance-biomarkers-and-predictors-champ-andquality-of-life 

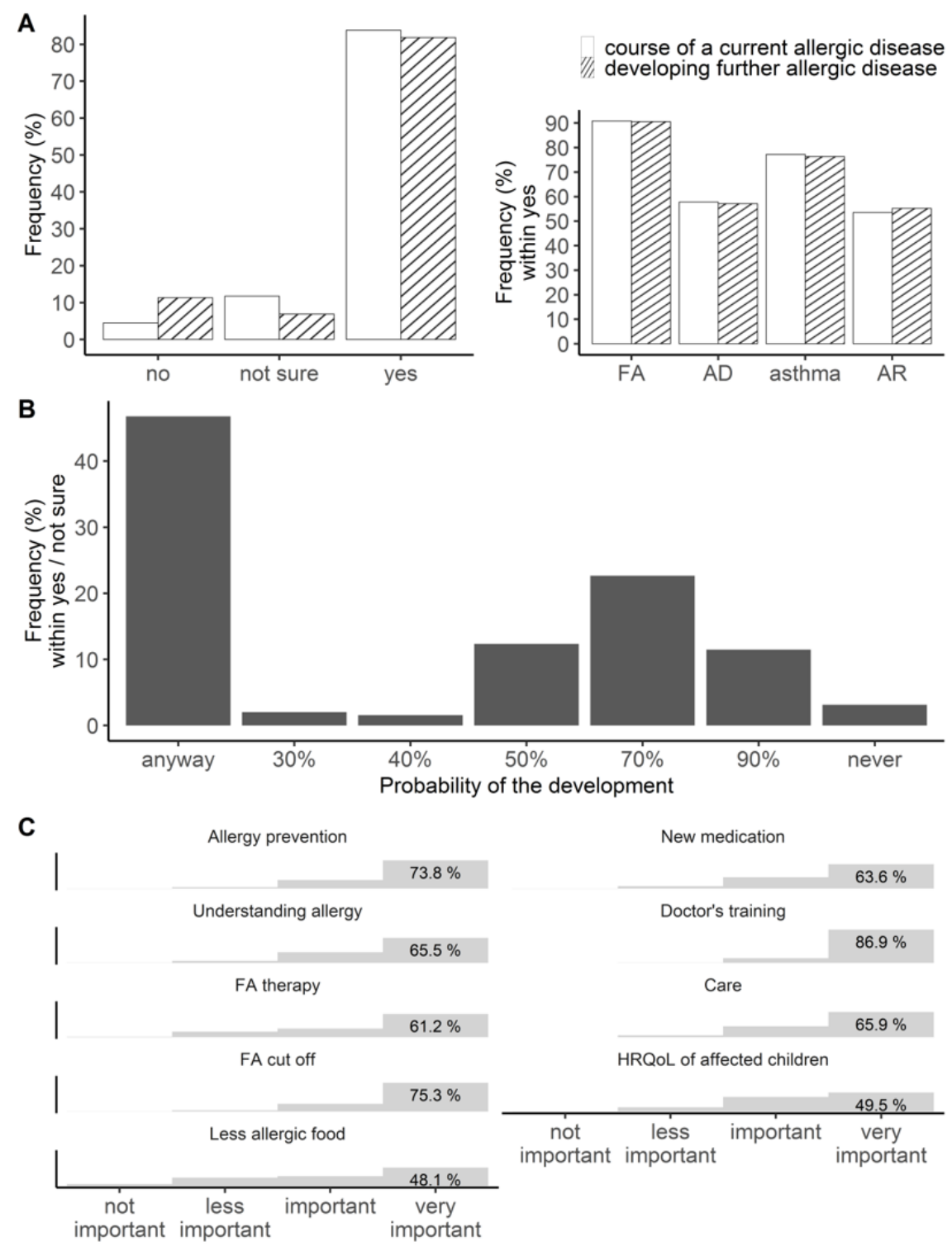